\title{
Comparison of thermal and light performance in two typical Chinese solar greenhouses in Beijing
}

\author{
Fan $\mathrm{Xu}^{1}$, Chao Shang ${ }^{1,2}$, Hongling $\mathrm{Li}^{3}$, Xuzhang Xue ${ }^{1}$, Weituo Sun ${ }^{1}$, Hong Chen ${ }^{1}$, \\ Yinkun $\mathrm{Li}^{1}$, Zhenhe Zhang ${ }^{4}$, Xinxu Li ${ }^{2}$, Wenzhong Guo ${ }^{1 *}$ \\ (1. Beijing Research Center of Intelligent Equipment for Agriculture, Beijing Academy of Agriculture and Forestry Sciences, Beijing 100097, \\ China; 2. Plant Science and Technology College, Beijing University of Agriculture, Beijing 102206, China; 3. Beijing Extension Station \\ for Agricultural Technology, Beijing 100101, China; 4. National Agricultural Technology Extension and Service Center, Ministry of \\ Agriculture and Rural Affairs of the People's Republic of China, Beijing 100125, China)
}

\begin{abstract}
Solar greenhouses have been used for producing vegetables in northern China during early spring, late autumn or over-winter. To improve the thermal performance of solar greenhouses, a traditional type and a retrofitted design were comparatively evaluated. In the retrofitted design, three adjustments were incorporated: the material and structure of the walls, south-facing roof angle, and structure of the north-facing back-roof. The results indicated that the thermal and light performance of the retrofitted greenhouse was much better than that of the traditional greenhouse. Specifically, the daily mean temperature, minimum air temperature, and soil temperature inside the greenhouses after retrofit ting were increased by $1.3,2.4$ and $1.9^{\circ} \mathrm{C}$, respectively, meanwhile, the daily total solar radiation and PAR were increased by $28.2 \%$ and $9.2 \%$, respectively. The wall temperature and its daily variation range were reduced with increasing depth and height. The characteristic analysis of heat storage and release indicated that higher locations have longer heat storage, and shorter heat release time in vertical direction, as well as a lower ratio of heat release to storage. In horizontal direction, the western wall has the shortest heat storage time but the highest heat release flux density. Altogether, the heat storage time of the wall is $1.5 \mathrm{~h}$ less than that of the soil. The heat storage flux density of the wall is 1.5 times of that of the soil, but the heat release flux is only $61 \%$ of the soil's value. The total wall heat storage is half of that of the soil in the greenhouse; the total wall heat release amount is only a quarter of that of the soil. Therefore, the thermal environment of solar greenhouses can be further improved by improving the thermal insulation properties of the wall.
\end{abstract}

Keywords: structural change, heat storage performance, heat flux, back wall, thermal environment DOI: $10.25165 /$ j.ijabe.20191201.3829

Citation: Xu F, Shang C, Li H L, Xue X Z, Sun W T, Chen H, et al. Comparison of thermal and light performance in two typical Chinese solar greenhouse in Beijing. Int J Agric \& Biol Eng, 2019; 12(1): 24-32.

\section{Introduction}

The Chinese solar greenhouses are energy-saving facilities due to their long growing season with no heating requirement. In northern China, solar greenhouses are usually used for producing vegetables during early spring, late autumn and over-winter. The thermal and light conditions are the two major indexes of a solar

Received date: 2017-10-17 Accepted date: 2018-12-12

Biographies: Fan $\mathrm{Xu}, \mathrm{PhD}$, Senior Engineer, research interest: greenhouse environment and control, Email:luckyfan@126.com; Chao Shang, Master student, research interests: facility vegetables and environment, Email: 15131276651@163.com; Hongling Li, Researcher, research interests: protected horticulture and olericulture, Email:lihongling1@sohu.com; Xuzhang Xue, PhD, Researcher, research interests: facility environment and production, Email: xuexz@nercita.org.cn; Weituo Sun, Engineer, research interest: greenhouse thermal environment, Email: sunwt@nercita.org.cn; Hong Chen, Engineer, research interests: greenhouse structure and environment, Email: chenh@nercita.org.cn; Yinkun Li, PhD, Senior Engineer, research interests: greenhouse environment and vegetables production, Email: liyk@nercita.org.cn; Zhenhe Zhang, Researcher, research interests: horticulture facility structure and design, Email: zhzhe@126.com; Xinxu Li, Senior Engineer, research interests: greenhouse environment and vegetable industrialized production, Email: 1xx4553562@163.com.

*Corresponding author. Wenzhong Guo, PhD, Researcher, research interests: facility horticulture and agriculture intelligent equipment. Beijing Research Center of Intelligent Equipment for Agriculture, Beijing Academy of Agriculture and Forestry Sciences, Beijing 100097, China. Tel: +86-10- 51503675; Fax: +86-10-51503504, Email: guowz@nercita.org.cn. greenhouse. The environment of a solar greenhouse mostly depends on the building materials and structure. There were also many sub-systems that tried to improve the thermal environment of solar greenhouses, e.g. heat collection and release system ${ }^{[1]}$, heat pump system ${ }^{[2]}$, and dual-roof design ${ }^{[3]}$. Most solar greenhouses can provide a suitable micro-climate for growing crops and plants, able to produce most kinds of vegetables over-winter, especially fruit vegetables ${ }^{[4,5]}$. However, some greenhouses were built in the early days with a simple structure and lower building cost, which have lower heat storage and preservation capability and only suitable to produce leaf vegetables during over-winter period. The performance of these types of greenhouses restricts their usage, and the solar utilization rate is lower than greenhouses for over-winter fruit vegetable production. Therefore, it is necessary to increase the usage efficiency by adjusting the greenhouse structure and retrofitting the old simple greenhouses, which can improve the greenhouse thermal environment.

Solar radiation is the sole energy source in Chinese solar greenhouses. Solar energy entered into greenhouses can be absorbed and stored by walls and soil in the daytime, then released for greenhouse heating in the nighttime ${ }^{[6,7]}$. The structures and the materials play important roles in heat storage and release in solar greenhouses. Indoor soil and the back wall are the two primary sources for heat storage and release, so optimizing the structure and materials of the back wall is very useful for greenhouse thermal performance improvement ${ }^{[8,9]}$. Intensive studies have been 
focused on the structure and functions of the back wall for years ${ }^{[10-15]}$, and the role of the back wall in the greenhouse thermal environment was investigated by exploration on different wall materials, structures and construction methods. Huang X. and Huang X., et $a l^{[16,17]}$ studies a thermal stability layer in the back wall, shows that simply increase the thickness of the back wall cannot continuously improve its performance. Currently, there are many studies focusing on heat transfer of the wall and the soil, but mostly in the soil wall greenhouses ${ }^{[18-20]}$. Heat flux analysis and simulation can reflect the heat insulation performance of the back wall ${ }^{[21-23]}$, especially heat release during the night ${ }^{[24]}$. Many methods have been proposed in former studies to retrofit simple solar greenhouses and improve the thermal and light environment. According to these studies and considering the structure and the climate of simple greenhouse, this study choose one proposed program to reconstruct the simple greenhouses.

The site of this study located in Daxing District $\left(116.33^{\circ} \mathrm{E}\right.$, $39.73^{\circ} \mathrm{N}$ ), south part of Beijing, China. In recent years, researchers and farmers have paid increasing attention to improve the greenhouse environment and accomplish fruit vegetables year-round production. However, some simple solar greenhouses built by experience years ago were not precisely calculated before construction, and they are mainly used for leaf vegetable production. Therefore, the thermal performance of these greenhouses needs to be improved by scientific methods.

In this study, a new solar greenhouse (NSG) was designed and retrofitted based on the old traditional simple solar greenhouse (OSG), including adjustments on the wall, the lighting angle of south-facing roof, and the north-facing back roof. The NSG was designed by Prof. Zhang $\mathrm{Z} \mathrm{H}$, the chief expert on greenhouse design in China. The structural parameters were calculated precisely according to the local climate, the radiation conditions, the greenhouse type and the growing requirements. The thermal and light environment of the OSG and NSG were tested. Composite walls was suggested in reconstruction, and heat storage and insulation materials were added to the inner and outer layers, respectively, which distinguishes the function of the solar greenhouse wall. The purpose of this study is to state the reconstruction project, test the environment and thermal performance of the back wall in the NSG and compare it with an OSG, and then evaluate the effect of retrofit on the greenhouse thermal environment, especially the contributions of the three structural changes to the thermal and light performance of solar greenhouses.

\section{Materials and methods}

\subsection{Description of the greenhouses and reconstruction program}

The solar greenhouses consisted of a back wall, a gable wall, a south roof, a back roof, and a buffer room, which were in the east-west direction. Two typical greenhouses were studied in the experiment for comparison: one NSG built according to scientific calculations and one OSG built according to experience. The old greenhouse cannot be used for fruit vegetable production over-winter due to its low night temperature in severe winters. To improve the thermal environment, this study aimed to enhance the energy inflow into the greenhouse and increase the heat storage during the day, with the addition of heat release at night. The NSG was rebuilt from an OSG, with the main changes on the wall, the lighting angle, and the back roof (Figure 1).

The retrofit program is as follow:
The OSG is described as follows: the greenhouse walls are thin, with a total thickness of $430 \mathrm{~mm}$. They were built with inner $400 \mathrm{~mm}$ hollow concrete block and outer $30 \mathrm{~mm}$ polyethylene board, and their height is $2.25 \mathrm{~m}$. The thickness of the back roof is $30 \mathrm{~mm}$, and the lighting angle is $23.7^{\circ}$.

The NSG is as follows: in retrofit, the old thin wall was preserved, and the height of the back wall was increased to $2.9 \mathrm{~m}$ with hollow concrete blocks; the wall thickness of $740 \mathrm{~mm}$ was composed of $240 \mathrm{~mm}$ red brick, $400 \mathrm{~mm}$ hollow concrete block, and $100 \mathrm{~mm}$ polyethylene board instead of $30 \mathrm{~mm}$ in OSG (Figure 1). The thickness of the back roof is increased to $100 \mathrm{~mm}$, and the lighting angle is increased to $35^{\circ}$.

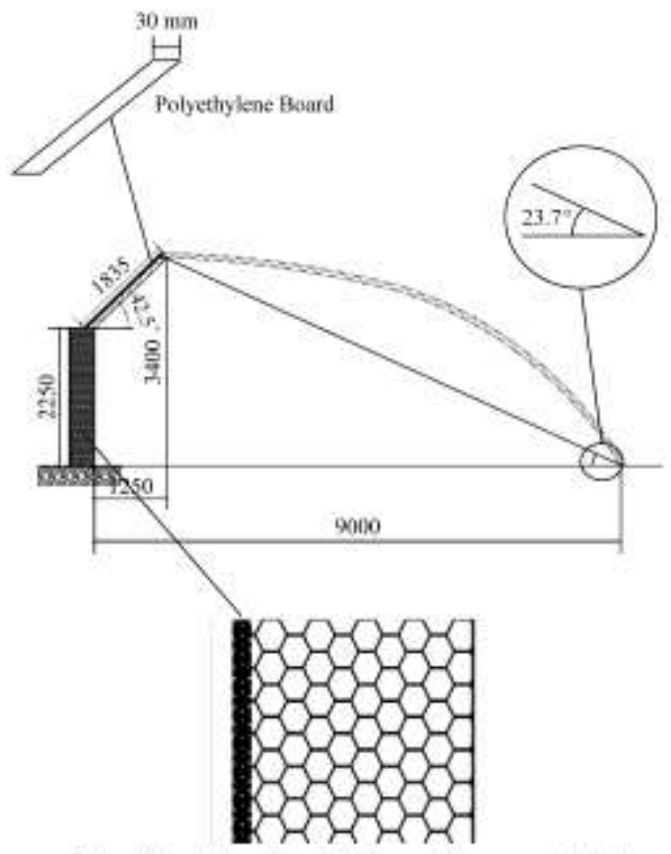

$30 \mathrm{~mm}$ Folyethylene Board + $400 \mathrm{~mm}$ hollow cosenete hlock a. Traditional solar greenhouse (OSG)
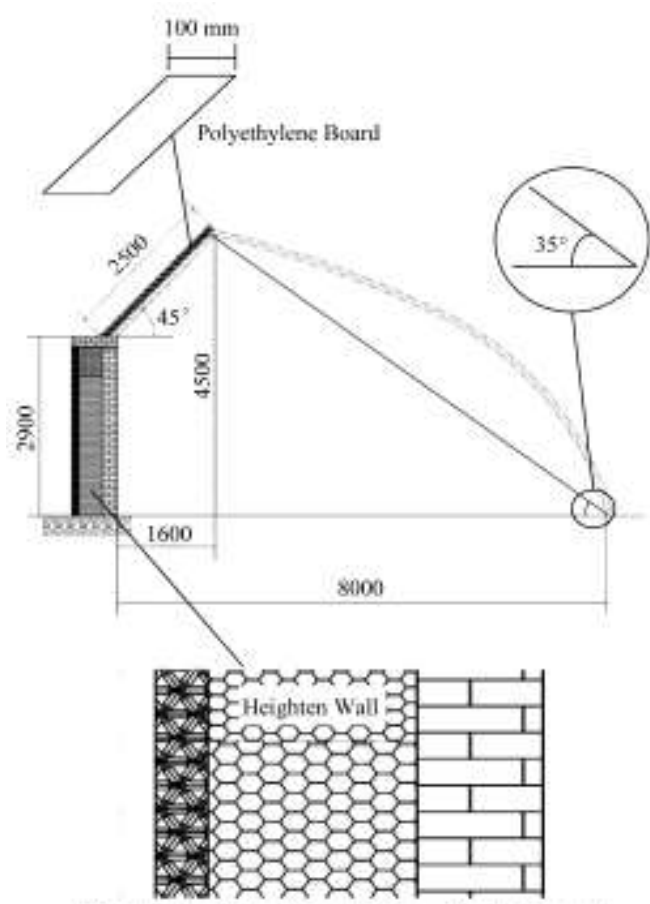

$106 \mathrm{~mm}$ Polyethylene Board $+400 \mathrm{~mm}$ Hollow Concrete Block $+240 \mathrm{~mm}$ Red Brick

b. New retrofitted solar greenhouse (NSG)

Figure 1 Design of the two greenhouses and their North-facing walls used in this study 
The structural parameters of the two typical greenhouses are shown in Table 1. And the outside insulation blankets were used during night. They were applied at 15:30 to 17:00 PM and removed at next 8:30 to 10:00 AM according to the season and weather.

Table 1 Structural parameters of the old simple greenhouse (OSG) and the new reconstructed greenhouse (NSG)

\begin{tabular}{lcc}
\hline \multicolumn{1}{c}{ Parameters } & OSG & NSG \\
\hline Length/m & 90 & 90 \\
Net span/m & 9 & 8 \\
Ridge height $/ \mathrm{m}$ & 3.4 & 4.5 \\
Back wall height $/ \mathrm{m}$ & 2.25 & 2.9 \\
Wall thickness $/ \mathrm{mm}$ & 430 & 740 \\
South roof lighting angle $/\left(^{\circ}\right)$ & 23.7 & 35 \\
Back roof angle $/\left(^{\circ}\right)$ & 42.5 & 45 \\
Back roof thickness $/ \mathrm{mm}^{\circ}$ & 30 & 100 \\
Back roof horizontal projection length $/ \mathrm{m}$ & 1.25 & 1.6 \\
\hline
\end{tabular}

The experiment was conducted for two consecutive winters from 2013 to 2015. Cucumbers or watermelons were planted in the NSG for over-winter production, and leaf vegetables or watermelons were planted in the OSG mainly for early spring and late autumn production.

\subsection{Measurement and analysis methods}

The air temperature, relative humidity, solar radiation, photo-synthetically active radiation (PAR) and soil temperature in the two greenhouses were measured by an agricultural microclimate monitoring system. The sensors and their parameters are shown in Table 2.

Table 2 The sensors of the agricultural microclimate system

\begin{tabular}{cccc} 
Sensor type & Measurement items & Measurement range & Company and States \\
\hline HMP155A & Air temperature & $-80^{\circ} \mathrm{C}-60^{\circ} \mathrm{C}$ & Vaisala; USA \\
& Relative humidity & $0-100 \%$ & \\
LI200X & Solar radiation & $0-1000 \mathrm{~W} / \mathrm{m}^{2}$ & Li-Cor; USA \\
LI190SB & $\begin{array}{c}\text { Photo-synthetically } \\
\text { active radiation }\end{array}$ & $0-2000 \mu \mathrm{mol} \cdot \mathrm{m}^{-2} \cdot \mathrm{s}^{-1}$ & Li-Cor; USA \\
109 & Soil temperature & $-50^{\circ} \mathrm{C}-70^{\circ} \mathrm{C}$ & $\begin{array}{c}\text { Campbell Scientific, } \\
\text { Inc; USA }\end{array}$ \\
\hline
\end{tabular}

In the NSG, the temperatures of the back wall at different heights and depths were measured with thermocouples (T-type, China). The heat flows of the wall surface and soil surface were measured with the heat flux plates HFP01 (Hukseflux, Holland).

The data were collected and recorded by data loggers (CR1000, Campbell, USA) and recorded every $10 \mathrm{~min}$ (average over 10 mins).

Figure 2 shows the measurement points of the temperature along the back wall in the NSG. Five measurements were laid out in the vertical direction, seven in the horizontal direction (A) and six in the thickness direction (B).

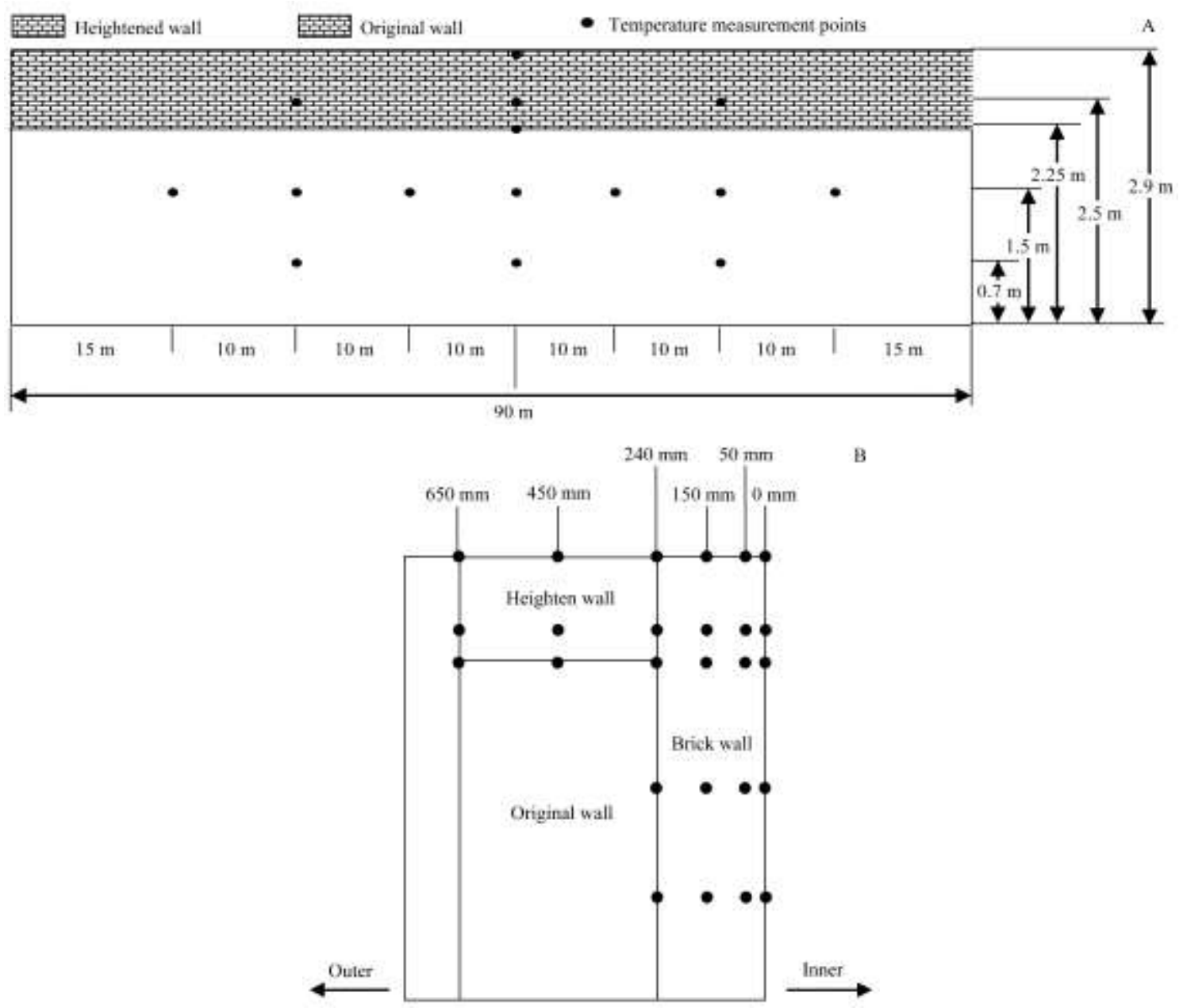

Figure 2 Temperature measurement points throughout the NSG wall shown in a front (A) and cross (B) view

The detailed temperature distributions of the back wall in time and space scales were then discussed. The heat transfer of the wall and soil surfaces was also studied to evaluate the thermal storage and insulation properties of the wall. The heat flows of surfaces inside the greenhouse were calculated by the following equations $^{[10]}$ :

$$
\begin{gathered}
q=\sum[H \cdot t] \\
Q=q \cdot S
\end{gathered}
$$


where, $H$ refers to the heat flow recorded by a thermal sensor at $10 \mathrm{~min}$ intervals, $\mathrm{W} / \mathrm{m}^{2} ; t$ refers to time, $\mathrm{s} ; S$ is the area of the surface, $\mathrm{m}^{2} ; q$ represents the heat flux per unit area, $\mathrm{MJ} / \mathrm{m}^{2}$; and $Q$ represents the heat flux over the entire area during the chosen period, MJ.

The heat released by the wall and soil can be used for greenhouse warming, and the air temperature rise was calculated by Equation (3):

$$
\Delta t=\frac{Q}{C_{p} \cdot \rho \cdot V}
$$

where, $Q$ refers to the heat flux over the entire area during the chosen period, $\mathrm{J} ; C_{p}$ refers to specific heat capacity, $\mathrm{J} \cdot \mathrm{kg}^{-1} \cdot{ }^{\circ} \mathrm{C}^{-1}$; $\rho$ refers to density, $\mathrm{kg} \cdot \mathrm{m}^{-3} ; V$ refers to volume, $\mathrm{m}^{3}$; and $\Delta t$ refers to temperature variation, ${ }^{\circ} \mathrm{C}$.

\section{Results and discussion}

\subsection{Air and soil temperatures in the greenhouses}

\subsubsection{Dynamics of air temperature and relative humidity}

Dynamic variations of the temperature in the two different greenhouses are described in Table 3. As the OSG wasn't used in January, the mean and minimum temperatures in this period were not involved. It can be seen that air temperatures in the NSG are almost consistently higher than those in the OSG from late November to early March the next year, with a daily mean temperature difference of $1.3^{\circ} \mathrm{C}$ and an average daily minimum temperature difference of $2.4^{\circ} \mathrm{C}$.

The extreme minimum temperatures in the OSG and NSG during production period were $-3.3^{\circ} \mathrm{C}$ and $0.2^{\circ} \mathrm{C}$, respectively. The daily maximum temperature of the OSG was higher than that of the NSG, which was due to the lower heat storage capacity of the OSG. So, the heat loss was faster, and the air temperature was lower at night in the OSG.

The relative humidity $(\mathrm{RH})$ of the OSG was higher than that of the NSG. In particular, the air RH during the day was approximately $10 \%$ higher in the OSG than the NSG, while both were close to $90 \%$ at night

Table 3 Air temperatures inside the two greenhouses during the winter months

\begin{tabular}{|c|c|c|c|c|c|c|}
\hline \multirow{2}{*}{$\begin{array}{c}\text { Greenhouse } \\
\text { Type }\end{array}$} & \multicolumn{6}{|c|}{ Daily mean temperature $/{ }^{\circ} \mathrm{C}$} \\
\hline & Late Nov & Dec & Jan & Feb & Early Mar & $\mathrm{AVG}^{*}$ \\
\hline NSG & 7.2 & 9.6 & 8.4 & 10.3 & 20.6 & 11.9 \\
\hline OSG & 5.0 & 6.3 & $2.1 * *$ & 10.5 & 20.5 & 10.6 \\
\hline \multirow{2}{*}{$\begin{array}{l}\text { Greenhouse } \\
\text { Type }\end{array}$} & \multicolumn{6}{|c|}{ Daily minimum temperature $/{ }^{\circ} \mathrm{C}$} \\
\hline & Late Nov & Dec & Jan & Feb & Early Mar & $\mathrm{AVG}^{*}$ \\
\hline NSG & 2.6 & 4.5 & 3.7 & 3.9 & 12.9 & 6.0 \\
\hline OSG & -0.2 & 0.5 & $-5.7 * *$ & 2.9 & 11.1 & 3.6 \\
\hline \multirow{2}{*}{$\begin{array}{l}\text { Greenhouse } \\
\text { Type }\end{array}$} & \multicolumn{6}{|c|}{ Daily maximum temperature $/{ }^{\circ} \mathrm{C}$} \\
\hline & Late Nov & Dec & Jan & Feb & Early Mar & $\mathrm{AVG}^{*}$ \\
\hline NSG & 15.4 & 17.8 & 16.6 & 22.1 & 35.4 & 22.7 \\
\hline OSG & 15.2 & 19.1 & $18^{* *}$ & 25.5 & 37.9 & 24.4 \\
\hline
\end{tabular}

Note: *The temperature in January was not included. **The mean and minimum temperatures of OSG in January were low because of the greenhouse didn't produce and the outside insulation blanket was not used, meanwhile the maximum temperature was high in January because the vents were not open.

Figure 3 shows the hourly variation of temperature and humidity in the greenhouses on a typical sunny day. The air temperature and humidity of the two greenhouses followed similar patterns over time. They raised and reduced with the solar radiation, but the rates of temperature increase and decrease were faster in the OSG than in the NSG. The RH of the OSG was higher than that of the NSG, especially during the daytime. And both of the two greenhouses were naturally ventilated via rolling up the plastic film. That indicates the insulation and ventilation performance of the NSG are better than that of the OSG.

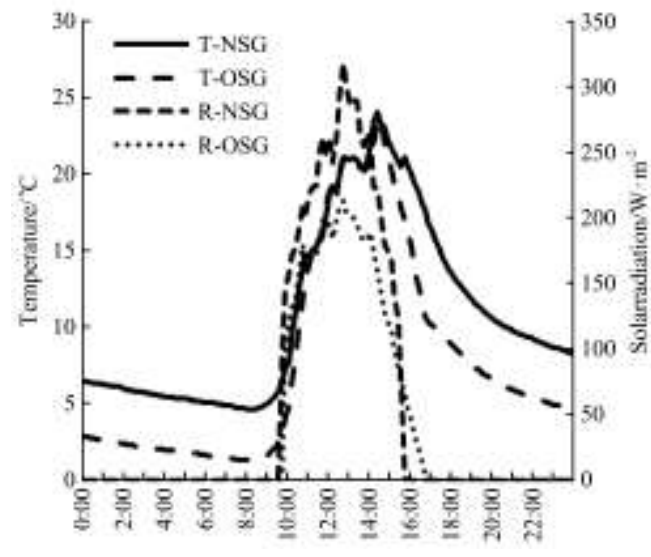

a. Temperature

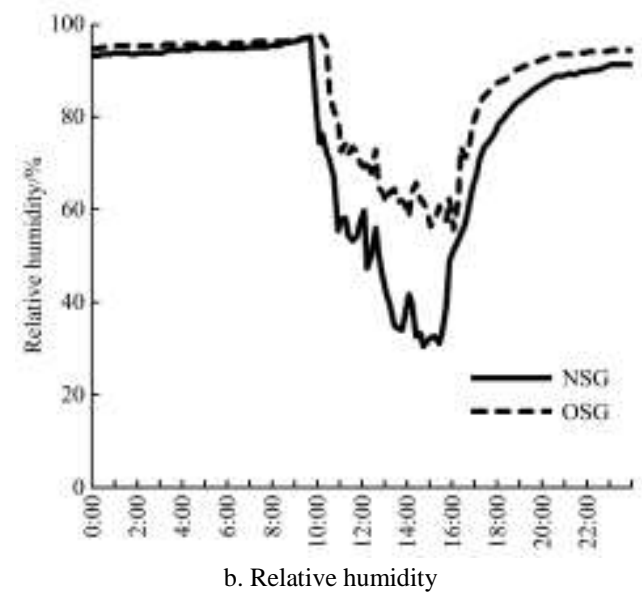

Figure 3 Hourly variations of temperature and relative humidity in the newly designed solar greenhouse (NSG) and the traditional solar greenhouse (OSG) on $29^{\text {th }}$, Dec., 2014

\subsubsection{Dynamics of soil temperature}

Soil temperature was measured at $5 \mathrm{~cm}$ depth and $10 \mathrm{~cm}$ depth in two greenhouses, the measurement points were $5 \mathrm{~m}$ west from the intermediate points in solar greenhouses. Results show that the soil temperature in the NSG was significantly higher than that in the OSG in winter (Figure 4). From late November to December, the NSG soil temperature fluctuated at $10^{\circ} \mathrm{C}$, and the OSG soil temperature fluctuated at $7{ }^{\circ} \mathrm{C}$. The soil temperatures of NSG are higher than that of OSG, but the temperatures had no significant difference between $5 \mathrm{~cm}$ and $10 \mathrm{~cm}$ depth in each solar greenhouse. The OSG didn't produce in January with outdoor insulation blanket uncovered, so the soil temperature was low to $0^{\circ} \mathrm{C}$ in some time. In March, the soil temperature in the two greenhouses increased markedly.

On average, the daily mean and minimum soil temperatures in the NSG were $1.9^{\circ} \mathrm{C}$ and $1^{\circ} \mathrm{C}$ higher than that in the OSG, respectively. Especially, compared with the OSG, the mean and minimum soil temperatures in the NSG in December were improved by $4^{\circ} \mathrm{C}$ and $3^{\circ} \mathrm{C}$, respectively. There was no significant difference in soil temperature between $5 \mathrm{~cm}$ and $10 \mathrm{~cm}$ depths in each solar greenhouse. In early March, the maximum soil temperature at $5 \mathrm{~cm}$ depth was a little higher than that at $10 \mathrm{~cm}$ (Table 4). 


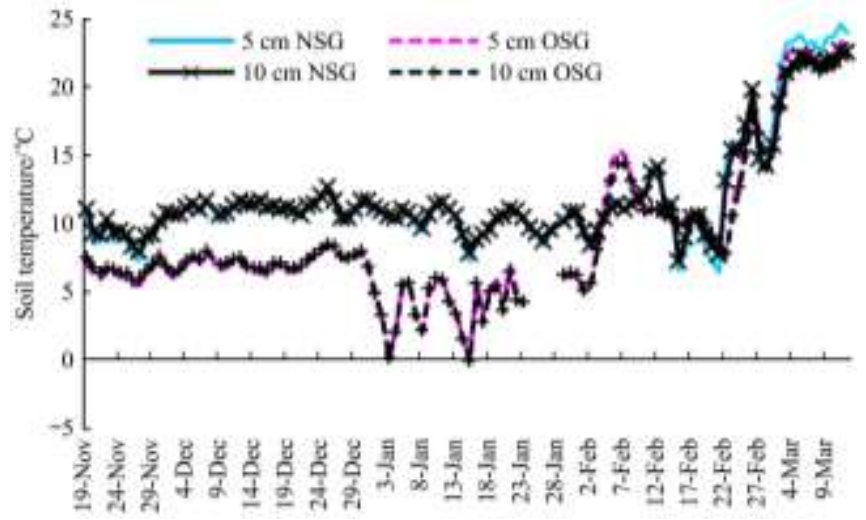

Figure 4 Daily variation of soil temperatures at different depths in the two greenhouses during the testing period

Table 4 Soil temperatures in two solar greenhouses during the testing period

\begin{tabular}{cccccccc}
\hline \multirow{2}{*}{$\begin{array}{c}\text { Greenhouse } \\
\text { type }\end{array}$} & Depth & \multicolumn{5}{c}{ Daily mean soil temperature/ ${ }^{\circ} \mathrm{C}$} \\
\cline { 3 - 8 } & /cm & Late Nov & Dec & Jan & Feb & Early Mar & AVG* \\
\hline \multirow{2}{*}{ NSG } & 5 & 8.9 & 11.1 & 10.1 & 11.6 & 22.5 & 13.5 \\
& 10 & 9.2 & 11.2 & 10.2 & 11.8 & 20.9 & 13.3 \\
\hline \multirow{2}{*}{ OSG } & 5 & 6.2 & 7.1 & $4.3 * *$ & 11.5 & 21.4 & 11.6 \\
& 10 & 6.5 & 7.3 & $4.2 * *$ & 11.2 & 20.5 & 11.4 \\
\hline
\end{tabular}

\begin{tabular}{cccccccc}
\hline \multirow{2}{*}{$\begin{array}{c}\text { Greenhouse } \\
\text { type }\end{array}$} & & \multicolumn{6}{c}{ Depth $/ \mathrm{cm}$ Daily minimum soil temperature $/{ }^{\circ} \mathrm{C}$} \\
\cline { 3 - 8 } & & Late Nov & Dec & Jan & Feb & Early Mar & AVG* \\
\hline \multirow{2}{*}{ NSG } & 5 & 7.0 & 9.1 & 8.4 & 7.4 & 18.3 & 10.5 \\
& 10 & 7.9 & 9.7 & 8.9 & 8.5 & 18.3 & 11.1 \\
\hline \multirow{2}{*}{ OSG } & 5 & 5.2 & 6.0 & $-1.1 * *$ & 9.1 & 17.8 & 9.5 \\
& 10 & 5.7 & 6.5 & $-1.4 * *$ & 9.5 & 18.0 & 9.9 \\
\hline
\end{tabular}

\begin{tabular}{cccccccc}
\hline \multirow{2}{*}{$\begin{array}{c}\text { Greenhouse } \\
\text { type }\end{array}$} & Depth $/ \mathrm{cm}$ & \multicolumn{5}{c}{ Daily maximum soil temperature/ ${ }^{\circ} \mathrm{C}$} \\
\cline { 3 - 8 } & & Late Nov & Dec & Jan & Feb & Early Mar & AVG* \\
\hline \multirow{2}{*}{ NSG } & 5 & 11.8 & 14.0 & 12.8 & 18.8 & 27.9 & 18.1 \\
& 10 & 11 & 13.1 & 11.9 & 17.3 & 23.4 & 16.2 \\
\hline \multirow{2}{*}{ OSG } & 5 & 7.4 & 8.2 & $15.2^{* *}$ & 14.4 & 25.4 & 13.9 \\
& 10 & 7.4 & 8.2 & $15.8 * *$ & 13.2 & 23.2 & 13.0 \\
\hline
\end{tabular}

Note: *The temperature in January was not included. **The mean and minimum temperatures of OSG in January were low because of the greenhouse didn't produce and the outside insulation blanket was not used, meanwhile the maximum temperature was high in January because the vents were not open.

The hourly variation of soil temperature in the two greenhouses on a sunny day is shown in Figure 5. It can be seen that the soil temperature had significant variations over a day, but the range is much narrower than the air temperature variation range as shown in Figure 3, and the soil temperature was higher than the inside air temperature during the night. The soil temperatures in the NSG are $2^{\circ} \mathrm{C}-6^{\circ} \mathrm{C}$ higher than those in the OSG, and the daily temperature range in the NSG $\left(8^{\circ} \mathrm{C}\right.$ to $\left.15^{\circ} \mathrm{C}\right)$ was also greater than that in the OSG $\left(6^{\circ} \mathrm{C}\right.$ to $\left.9^{\circ} \mathrm{C}\right)$. It is clear that the $5 \mathrm{~cm}$ soil near the surface undergoes rapid heating during the day and fast cooling at night, and its temperature change is greater than that at a depth of $10 \mathrm{~cm}$. Therefore, the soil temperature variation range decreases with increasing depth in all greenhouses in winter.

\subsection{Dynamics of solar radiation and PAR}

Solar radiation is the sole source of incoming energy. Stronger solar radiation provides more solar to the greenhouse, leads to faster indoor temperature rises in winter. The total solar radiation is much higher in the NSG than the OSG (Table 5), which is directly due to the improvement of the south roof lighting angle
(Figure 1). During the testing period, the total amount of solar radiation in the NSG $\left(4.77 \mathrm{MJ} / \mathrm{m}^{2}\right)$ was $28.2 \%$ higher than that of the OSG $\left(3.72 \mathrm{MJ} / \mathrm{m}^{2}\right)$. The light condition of the NSG was better than that of the OSG from late November to February. Compared with the OSG, the total radiation of the NSG in December, January and February was increased by $31.2 \%, 62.0 \%$ and $121.3 \%$ respectively. However, in March, the total solar radiation of the OSG was higher than that of the NSG due to the change of solar elevation angle. It indicates that the south-roof angle increase can improve winter lighting and reduce spring and summer lighting, which will benefit the vegetable growth.

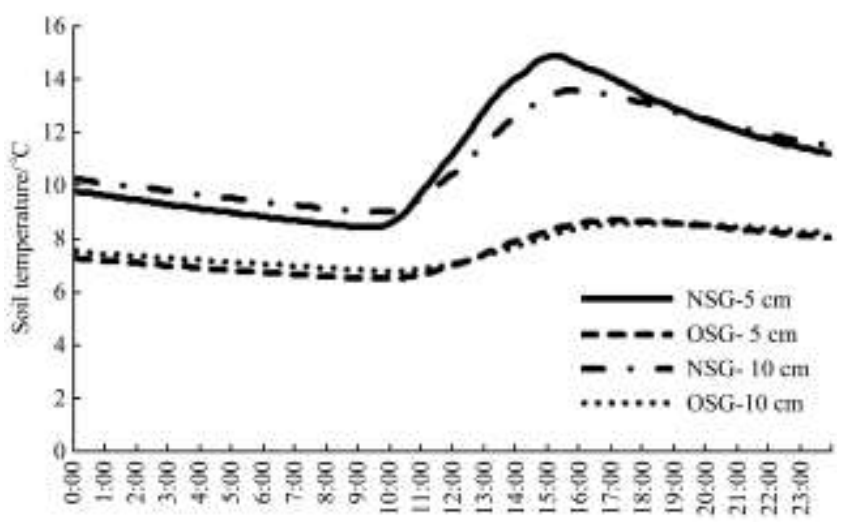

Figure 5 Hourly variations of soil temperatures in the two greenhouses on sunny days

Table 5 Total solar radiation in two typical solar greenhouses

\begin{tabular}{cccccc}
\hline \multirow{2}{*}{$\begin{array}{c}\text { Greenhouse } \\
\text { type }\end{array}$} & \multicolumn{5}{c}{ Daily total solar radiation/MJ. $\mathrm{m}^{-2} \cdot \mathrm{d}^{-1}$} \\
\cline { 2 - 6 } & Late Nov & Dec & Jan & Feb & Early Mar \\
\hline NSG & 3.45 & 4.96 & 4.39 & 3.74 & 7.29 \\
OSG & 2.94 & 3.78 & 2.71 & 1.69 & 7.5 \\
\hline \multirow{2}{*}{$\begin{array}{c}\text { Greenhouse } \\
\text { type }\end{array}$} & Late Nov & Dec & Jan & Feb & Early Mar \\
\cline { 2 - 6 } & 228.7 & 328.4 & 302.9 & 251.5 & 426.2 \\
NSG & 195.6 & 254.2 & 179.2 & 124.8 & 480.7 \\
OSG &
\end{tabular}

Photo-synthetically active radiation (PAR) represents the part of the solar radiation that participates in plant photosynthesis. The PAR of the NSG is also improved compared with the OSG, but the proportional increase is not as significant as that of the total radiation (Table 6). During the testing period, the mean PAR values in the NSG and OSG were $79.32 \mu \mathrm{mol} / \mathrm{m}^{2}$. s and 72.64 $\mu \mathrm{mol} / \mathrm{m}^{2} \cdot \mathrm{s}$, respectively, with a $9.2 \%$ higher of NSG than OSG. From December to February, the PAR in the NSG was better than that in the OSG; the PAR and daily light integral increased by $11.5 \%, 42.9 \%$ and $62.8 \%$ in December, January and February respectively; but in late November and early March, the PAR in the OSG was higher than that in the NSG. This is mainly due to the lighting angle of the south roof and the transmittance of the greenhouse film.

As shown in Table 5, Table 6 and Figure 6, the total solar radiation was improved more than the PAR due to the reconstruction of the south roof angle, indicates more obvious heating effect. PAR increased significantly in winter (December to February). In March, the total solar radiation and PAR both increased over 2 times in the NSG with the increase of solar elevation angle, whereas those of the OSG increased 3-4 times.

In addition, both of the total solar radiation and PAR in late November were lower than those in December because of the continuous cloudy day in late November. 
Table 6 Photo-synthetically active radiation (PAR) in the two greenhouses

\begin{tabular}{cccccc}
\hline \multirow{2}{*}{$\begin{array}{c}\text { Greenhouse } \\
\text { Type }\end{array}$} & \multicolumn{5}{c}{ Daily mean PAR $/ \mu \mathrm{mol} \cdot \mathrm{m}^{-2} \cdot \mathrm{s}^{-1}$} \\
\cline { 2 - 6 } & Late Nov & Dec & Jan & Feb & Early Mar \\
\hline NSG & 59.4 & 81.7 & 70.9 & 56 & 128.6 \\
OSG & 61 & 73.3 & 49.6 & 34.4 & 144.9 \\
\hline \multirow{2}{*}{$\begin{array}{c}\text { Greenhouse } \\
\text { Type }\end{array}$} & Late Nov & Dec & Jan & Feb & Early Mar \\
\cline { 2 - 6 } & 345.5 & 463.5 & 419.1 & 322.9 & 650 \\
\hline NSG & 344.7 & 415.7 & 280.8 & 215.9 & 774.3 \\
OSG & & Daily light integral $/ \mathrm{mole}^{-2} \mathrm{~m}^{-2} \cdot \mathrm{d}^{-1}$ & \\
\hline \multirow{2}{*}{ Greenhouse } & & Dec & Jan & Feb & Early Mar \\
\cline { 2 - 6 } Type & Late Nov & DAR $/ \mu \mathrm{mol} \cdot \mathrm{m}^{-2} \cdot \mathrm{s}^{-1}$ & \\
\hline NSG & 5.13 & 7.06 & 6.13 & 4.84 & 11.11 \\
OSG & 5.27 & 6.33 & 4.29 & 2.97 & 12.52 \\
\hline
\end{tabular}

The hourly variations of total solar radiation and PAR in the greenhouses on a sunny day are shown in Figure 6. It also indicates that the effect of the structure alteration on total radiation was larger than that on PAR. The solar radiation and PAR both rose with the removing of the external insulation blanket (it is used during night for thermal insulation), reaching its peak at approximately 13:00, and then fell gradually until the external insulation blanket closed.
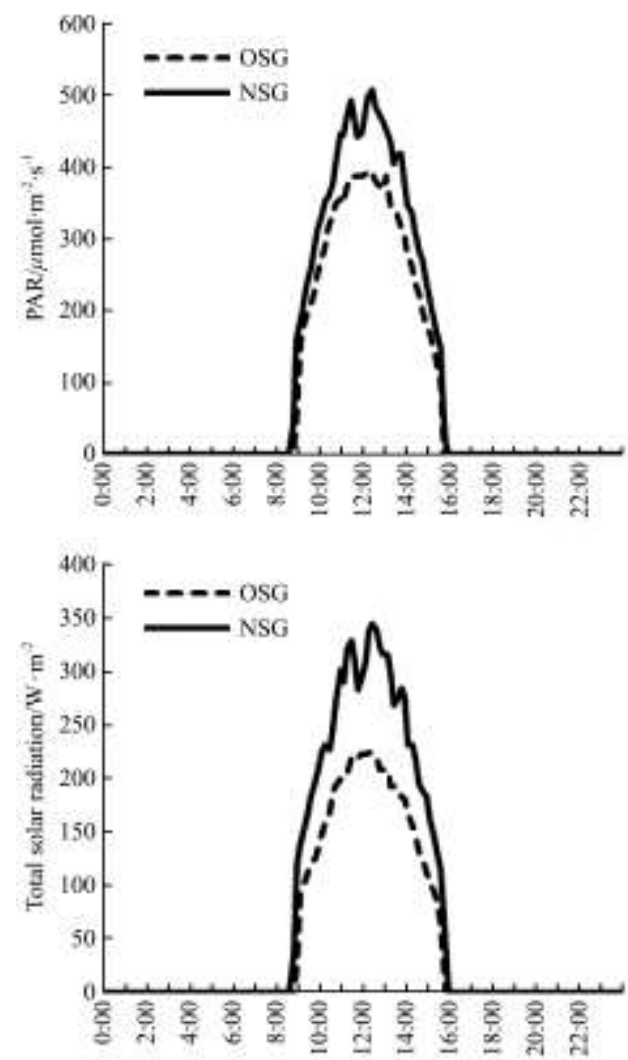

Figure 6 Hourly variation of total solar radiation and PAR in the two greenhouses on a sunny day, December 12th, 2014

\subsection{Heat transfer of different surfaces}

Heat flow represents the heat transfer of the wall/soil surface, and heat flux intensity is a measure of heat storage or release by the wall and soil. The heat flux of the wall/soil surface were measured in this study, the measuring locations were in the middle of east-west in solar greenhouse. For the wall surface, in vertical direction, three different heights of $0.7 \mathrm{~m}, 1.5 \mathrm{~m}$ and $2.25 \mathrm{~m}$ were tested; in horizontal direction, three locations were measured at the height of $1.5 \mathrm{~m}$, they are the middle, the east and west sides at a $10 \mathrm{~m}$ distance from the middle (Figure 2).

\subsubsection{Heat transfer of the wall surface at different heights}

The heat transfer of the wall surface at different heights is presented in Table 7 and Figure 7 . The heat storage and release time changes with the height of the wall, higher locations always have longer heat storage time and shorter heat release time. The average heat storage flux has the highest value in the middle of the wall, followed by the upper position, and the lower position has the lowest heat storage flux. The average heat release flux was still the highest in the center, followed by the low position, and the lowest heat release flux was detected in the high position. The average heat release was approximately $40 \%$ of the heat storage. The proportion of heat release to heat storage at different heights was $57.6 \%$ at $0.7 \mathrm{~m} ; 46.2 \%$ at $1.5 \mathrm{~m}$ : and $19.7 \%$ at $2.25 \mathrm{~m}$. It means that although the highest position on the wall had higher heat storage, its heat release was the lowest due to heat loss caused by longitudinal heat transfer.

Table 7 Heat storage and release characteristics at different back wall heights of NSG

\begin{tabular}{lcccc}
\hline \multicolumn{1}{c}{ Projects } & $0.7 \mathrm{~m}$ & $1.5 \mathrm{~m}$ & $2.25 \mathrm{~m}$ & AVG \\
\hline Heat storage time $/ \mathrm{h}$ & 7 & 7 & 8 & 7.5 \\
Heat release time/h & 17 & 17 & 16 & 16.7 \\
Heat storage flux $/ \mathrm{W} \cdot \mathrm{m}^{-2}$ & 65.66 & 87.87 & 74.05 & 75.9 \\
Heat release flux $/ \mathrm{W} \cdot \mathrm{m}^{-2}$ & 15.60 & 16.61 & 7.34 & 13.2 \\
Heat storage $q / \mathrm{MJ} \cdot \mathrm{m}^{-2}$ & 1.65 & 2.21 & 2.13 & 2.0 \\
Heat release $q / \mathrm{MJ} \cdot \mathrm{m}^{-2}$ & 0.95 & 1.02 & 0.42 & 0.8 \\
\hline
\end{tabular}

The hourly heat flow variation shows a double-peak curve in Figure 7. The decrease at noon was caused by the shade of the middle insulation blanket, which was not removed in the greenhouse management for the whole day. In Figure 7, the positive values indicate that the temperature of the wall surface was higher, and the surface absorbed heat, transferred and stored it into the inner wall, while the negative values represent the heat released from the wall surface. It can be seen that the state of insulation cover has greater impact on the lower heights of $0.7 \mathrm{~m}$ and $1.5 \mathrm{~m}$ than that on the $2.25 \mathrm{~m}$ part. The heat storage time at $1.5 \mathrm{~m}$ is shorter, while its heat flux ranks the first with a peak value of $150 \mathrm{~W} / \mathrm{m}^{2}$. And the heat release time at $1.5 \mathrm{~m}$ is longer, while its heat release flux ranks the lowest with a maximum value of only $19.72 \mathrm{~W} / \mathrm{m}^{2}$. The heat storage time at $2.25 \mathrm{~m}$ is obviously the highest among all heights, but the heat release time is the shortest.

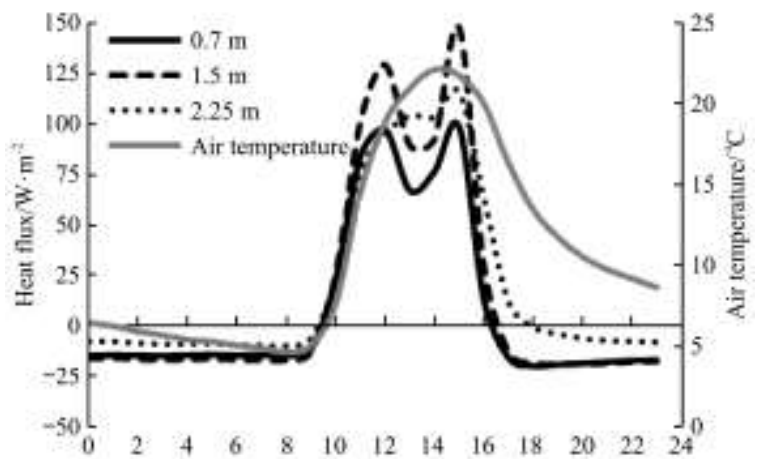

Figure 7 Hourly variation of heat flux at the inside of the South-facing wall surface at different heights

3.3.2 Heat transfer of the back wall at different horizontal positions

The variation of heat flow in the horizontal direction is 
measured at the height of $1.5 \mathrm{~m}$, and results were shown in Table 8 . This height has the longest heat storage time and the most amount of total heat storage, but the heat flux intensity of the middle was not the highest because of the effect of thermal insulation cover. The highest heat flux intensity was detected at the western side of the back wall at $92.55 \mathrm{~W} / \mathrm{m}^{2}$, followed by the middle wall at $87.87 \mathrm{~W} / \mathrm{m}^{2}$ and the lowest of $79.04 \mathrm{~W} / \mathrm{m}^{2}$ detected at the eastern side of the back wall. The heat release flux intensity was also the highest in the west, while the east and the middle had close value with each other. The average heat release accounted for $59.9 \%$ of the heat stored in the horizontal direction, and the proportion of heat release to heat storage was: $60 \%$ in the east, $46.2 \%$ in the middle and $75 \%$ in the west. Both sides of the wall were higher than that of the middle wall. The west wall had the highest thermal efficiency due to its low heat loss.

Table 8 Heat storage and release at different wall locations in the horizontal direction

\begin{tabular}{lcccc}
\hline \multicolumn{1}{c}{ Projects } & East & Middle & West & AVG \\
\hline Heat storage time/h & 6.5 & 7 & 6 & 6.5 \\
Heat release time $/ \mathrm{h}$ & 17.5 & 17 & 18 & 17.5 \\
Heat storage flux $/ \mathrm{W} \cdot \mathrm{m}^{-2}$ & 79.04 & 87.87 & 92.55 & 86.49 \\
Heat release flux $/ \mathrm{W} \cdot \mathrm{m}^{-2}$ & 17.60 & 16.61 & 23.08 & 19.10 \\
Heat storage $q / \mathrm{MJ} \cdot \mathrm{m}^{-2}$ & 1.85 & 2.21 & 2.00 & 2.02 \\
Heat release $q / \mathrm{MJ} \cdot \mathrm{m}^{-2}$ & 1.11 & 1.02 & 1.50 & 1.21 \\
\hline
\end{tabular}

Figure 8 shows the hourly variation of heat flux between the wall and the air at different locations in the horizontal direction. It can be seen that the hourly heat flux curve is a single-peak on the east and west side walls except on the middle wall, which is also because of the effect of the thermal insulation cover. A positive value represents heat absorbed, and a negative value represents heat released. The total heat flux of the middle wall was higher than that of the east and west side walls in the morning and the afternoon, and it can be inferred that if there is no shade, the heat storage density of the middle wall should be the highest. At night before 0:00, heat release flux density is the highest on the west wall and gradually reduced after 0:00, close to the east and middle walls.

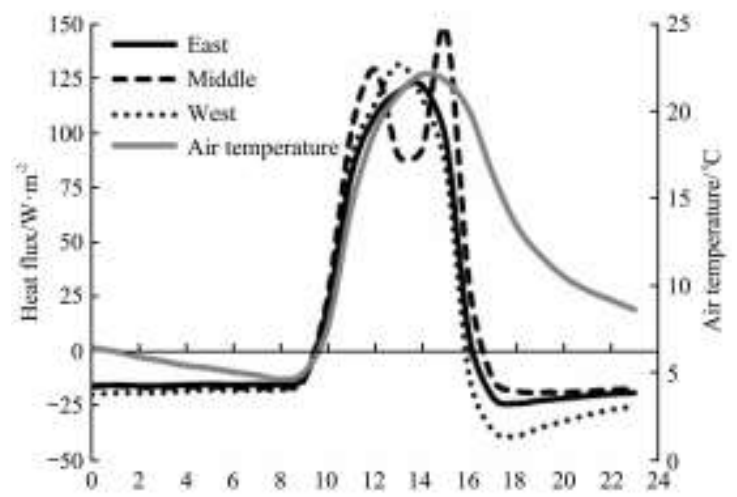

Figure 8 Hourly variation of the heat flux along the South-facing wall surface at different positions in the horizontal direction on a sunny day, December 29th, 2014

3.3.3 Heat flux comparison between the wall and the soil

In this study, the heat flow of the wall and the soil was measured simultaneously. A comparison of the heat flux between the wall surface and the soil is shown in Table 9. It can be seen that on a sunny day, the heat storage time of the wall surface was $1.5 \mathrm{~h}$ shorter than that of the soil surface, while the heat release time was $1.5 \mathrm{~h}$ longer than that of the soil surface. The average heat storage flux intensity of the wall was $27.51 \mathrm{~W} / \mathrm{m}^{2}$ higher than that of the soil surface, but the heat release flux intensity was $8.04 \mathrm{~W} / \mathrm{m}^{2}$ lower than that of the soil surface. Therefore, the heat storage of the wall is higher than that of the soil, while the heat release is lower. The proportion of soil heat release to heat storage was $68.1 \%$, whereas that of the wall was only $35.7 \%$. As the area of the soil is nearly 3 times that of the wall, the daily total soil heat storage is approximately 2 times of the wall heat storage, and the total heat release is approximately 4 times of the wall heat release.

Table 9 Contrast of heat flux between wall and soil surfaces

\begin{tabular}{lcc}
\hline \multicolumn{1}{c}{ Projects } & Wall surface & Soil surface \\
\hline Heat storage time $/ \mathrm{h}$ & 7.5 & 9 \\
Heat release time $/ \mathrm{h}$ & 16.5 & 15 \\
Heat storage flux $/ \mathrm{W} \cdot \mathrm{m}^{-2}$ & 78.82 & 51.31 \\
Heat release flux $/ \mathrm{W} \cdot \mathrm{m}^{-2}$ & 12.81 & 20.85 \\
Heat storage $q / \mathrm{MJ} \cdot \mathrm{m}^{-2}$ & 2.13 & 1.66 \\
Heat release $q / \mathrm{MJ} \cdot \mathrm{m}^{-2}$ & 0.76 & 1.13 \\
Daily total heat storage $Q / \mathrm{MJ}$ & 555.43 & 1196.93 \\
Daily total heat release $Q / \mathrm{MJ}$ & 198.53 & 810.57 \\
\hline
\end{tabular}

The heat released from the wall and the soil was used to heat up the indoor air. Compared with the OSG, the temperature during the night in the NSG was $4{ }^{\circ} \mathrm{C}$ higher. Equation (3) indicates that the indoor air needed to absorb $161.5 \mathrm{MJ}$ of heat energy to raise the temperature by $4^{\circ} \mathrm{C}$. During the same period, the total heat released by the wall and soil was $1009.1 \mathrm{MJ}$, which means that only $16 \%$ of the heat released from the wall and soil contributed to indoor heating, and $84 \%$ was lost in various forms.

\subsection{Temperature distribution of the back wall}

To evaluate the thermal storage and insulation performance of the back wall, the temperature distribution of the back wall was tested as shown in Table 10, while Figs. 9 and 10 shows the temperature in depth and vertical directions. It is clear that the wall temperature was affected by the indoor and outdoor temperature and solar radiation.

The daily mean temperature at different depths (Table 9) illustrates that deeper location has lower temperature. $\quad 0-250 \mathrm{~mm}$ depth is the heat storage layer of the wall, the temperature of which was significantly higher than that at $450-650 \mathrm{~mm}$. Just as the indoor air, the wall temperature was the lowest in January. The mean wall temperatures were $2.8^{\circ} \mathrm{C}$ and $2.2^{\circ} \mathrm{C}, 0.5^{\circ} \mathrm{C}$ higher than the indoor temperatures from Dec to the next Feb. The temperature of the 450-650 mm layer decreased rapidly (only $2^{\circ} \mathrm{C}$ $-5^{\circ} \mathrm{C}$ ), which indicates high heat loss. Therefore, further improvement of the greenhouse insulation properties will undoubtedly improve the solar greenhouse thermal environment.

Table 10 Daily mean temperatures of the NSG walls at different depths during the test period

Unit: ${ }^{\circ} \mathrm{C}$

\begin{tabular}{ccccccc}
\hline & \multicolumn{6}{c}{ Depth/mm } \\
\cline { 2 - 7 } Month & 0 & 50 & 150 & 250 & 450 & 650 \\
\hline Dec. & 12.4 & 12.1 & 10.5 & 9.1 & 4.0 & 2.6 \\
Jan. & 10.6 & 10.4 & 9.2 & 8.1 & 3.7 & 2.5 \\
Feb. & 10.8 & 10.5 & 9.4 & 8.5 & 5.1 & 4.1 \\
\hline
\end{tabular}

The hourly variation of wall temperatures at different depth layers in the NSG is shown in Figure 9. With the increase of solar radiation and indoor air temperature, the wall surface temperature rose rapidly to $18^{\circ} \mathrm{C}$ or more. During the night, the temperature 
continued to decline to value of $5.8^{\circ} \mathrm{C}$, accompanied by heat release from the wall and close to the air temperature before 9:00. Also, the temperature variation range gradually decreased with increasing wall depth, and the peak value gradually shifted backwards (the same results obtained by Zhang ${ }^{[25]}$ ), which indicated that the heat transfer in the wall during the day was transmitted from the inner surface to the outer. Temperatures at $250 \mathrm{~mm}$ depth and deeper are basically stable, the $250 \mathrm{~mm}$ depth temperature is approximately $6^{\circ} \mathrm{C}$, and $250--450 \mathrm{~mm}$ is the thermal stability layer. Therefore, the brick wall thermal storage layer is suggested to be $250-300 \mathrm{~mm}$ in this study, and that of the soil wall was suggested to be $385 \mathrm{~mm}^{[26]}$. Particularly, the hourly temperature at $650 \mathrm{~mm}$ reached the maximum at 23:00 and declined to the minimum at 10:00 because of the heat transfer from the inner wall and good insulation performance of the hollow concrete block and the polyethylene board.

To study the wall temperature changes with height, five points of $0.7 \mathrm{~m}, 1.5 \mathrm{~m}, 2.25 \mathrm{~m}$ (contact point of the new and the original wall), $2.5 \mathrm{~m}, 2.9 \mathrm{~m}$ (the highest point of the back wall, connected with the back roof) were tested. The results are shown in Figure 10. It can be seen that all the hourly temperature of the wall at different heights are single-peak curves, and lower position has larger temperature variation range. As the height increases, the wall temperature decreased gradually, except at $2.9 \mathrm{~m}$ due to extra solar radiation leaded temperature rise at noon. The lower walls temperature increase mainly depends on solar radiation and indoor heat transfer.

There was no significant difference among wall temperatures in the horizontal direction.

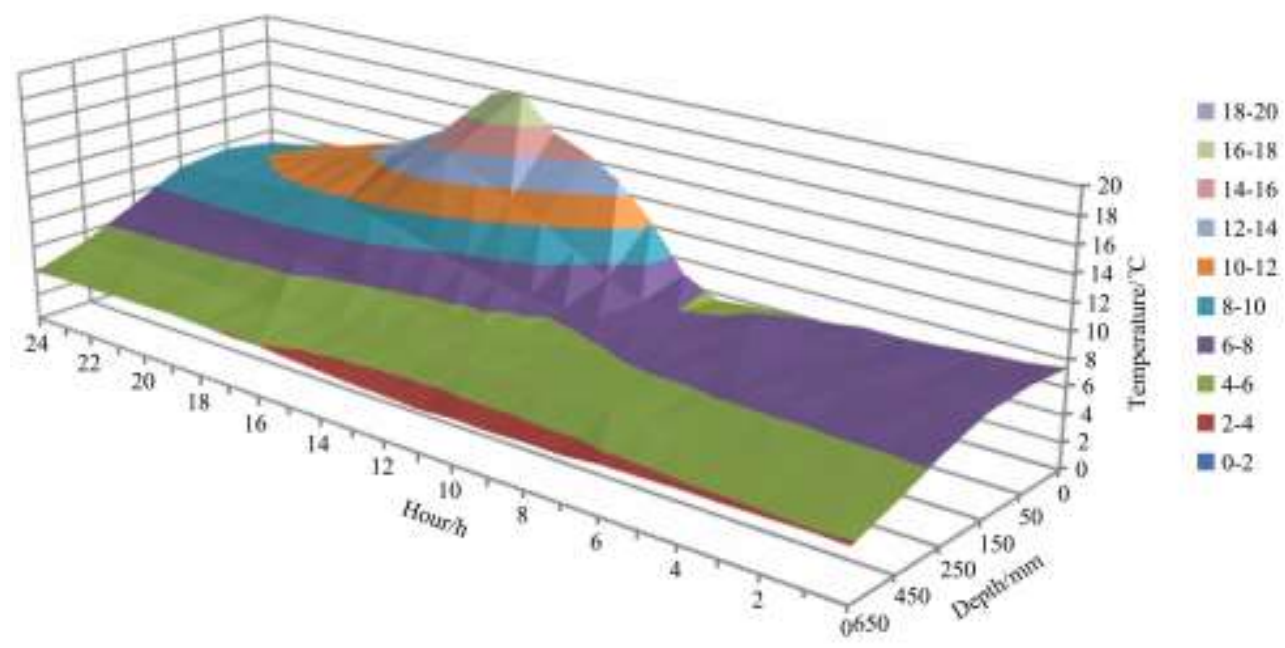

Figure 9 Hourly temperature distribution of the back wall at different depths on a typical sunny day

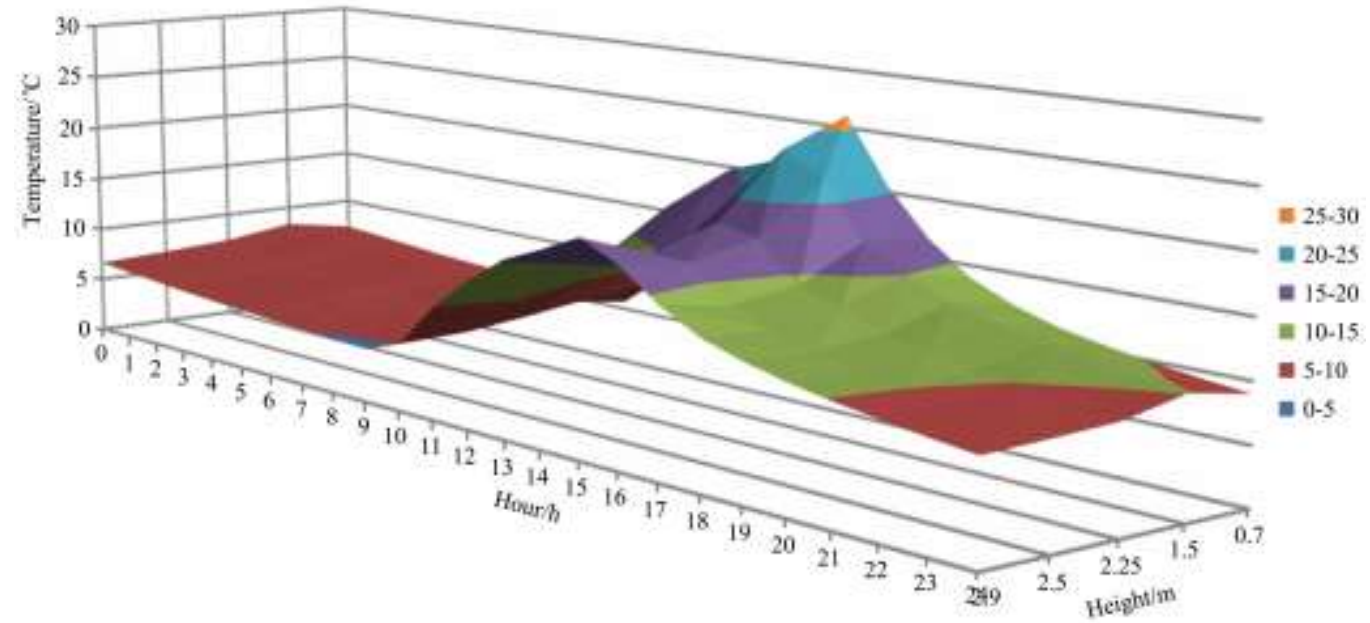

Figure 10 Hourly temperature distribution of the back wall at different heights on a sunny day

\section{Conclusions}

The structural modification increased the daily mean temperature, minimum temperature and soil temperature by $1.3^{\circ} \mathrm{C}$, $2.4^{\circ} \mathrm{C}$, and $1.9^{\circ} \mathrm{C}$, respectively; improved the total solar radiation and PAR by $28.2 \%$ and $9.2 \%$, respectively. The wall temperature distribution shows that the wall temperature decreases gradually with depth and height increased, and the temperature variation range becomes smaller. The brick wall thickness for heat storage is suggested to be $250-300 \mathrm{~mm}$. The heat transfer of the wall indicates that higher location always has a longer heat storage time and a shorter heat releasing time, and the amount of heat release was smaller than the amount of heat storage. In the horizontal direction, the heat storage time of the middle wall was the longest, followed by the east side. The heat storage time of the wall was $1.5 \mathrm{~h}$ less than that of the soil surface, and the average heat storage flux was 1.5 times of that of the soil. However, the average heat release flux density of the wall was only $61 \%$ of that of the soil surface. The total heat storage of the wall was $50 \%$ of that of the soil, but the total heat release was $25 \%$ of that of the soil because of the 3 times greater soil surface area. The heat utilization efficiency for indoor heating was only $16 \%$ of the heat released 
from the wall and the soil.

In the envelope structure of the solar greenhouse, the walls play an important role in maintaining the greenhouse thermal environment besides the ground ${ }^{[27]}$. Further improvement of the insulation performance of the walls will reduce the heat loss, save more heat for greenhouse warming and further improve the greenhouse's thermal environment. Increasing the south roof lighting angle improves the greenhouse light condition, so that more energy went into the greenhouse, conducive to enhancing the greenhouse thermal environment and improving the light condition, eventually benefit for plant photosynthesis. It can be seen that the retrofitted of the old traditional solar greenhouse provide an effective way to greatly enhance greenhouse thermal and lighting environment, which can produce the fruit and vegetables over-winter, extend the production time and improve the utilization of solar greenhouses.

\section{Acknowledgements}

The study was financially supported by the National Natural Science Foundation of China (31601794), International cooperation fund of Beijing Academy of Agriculture and Forestry Sciences (GJHZ2018-04), and the project of Facilities Horticulture Innovation Team of Beijing Academy of Agriculture and Forestry Sciences (JNKST201615).

\section{[References]}

[1] Fang H, Yang Q, Zhang Y, Sun W, Lu W, Liang H. Performance of a solar heat collection and release system for improving night temperature in a Chinese solar greenhouse. Applied Engineering in Agriculture, 2015; 31(2): 283-289.

[2] Chai L, Ma C, Ni J Q. Performance evaluation of ground source heat pump system for greenhouse heating in northern China. Biosystems Engineering, 2012; 111(1): 107-117.

[3] Chai L, Wang B, Liu M, Wu Z, Xu Y. Dual-roof solar greenhouse-a novel design for improving the heat preserving capacity in Northern China. Natural Resources, 2014; 5(12): 681.

[4] Li M, Wei X M, Qi F, Zhou C J. Research progress in wall of solar greenhouses. Xinjiang Agricultural Sciences, 2014; 51(6): 1162-1170, 1176. (in Chinese)

[5] Sun S J, Zhan C H, Yang G, Yu Y G. Research on a new technology integrated low-cost, near-zero-energy solar greenhouse. Procedia Engineering, 2016; 145: 188-195.

[6] Narjes D, Leila D. Experimental heat flux analysis of a solar wall design in Tunisia. Journal of Building Engineering, 2016; 8: 70-80.

[7] Prashant S C, Anil K. Performance analysis of greenhouse dryer by using insulated north-wall under natural convection mode. Energy Reports, 2016; 2: 107-116.

[8] Luo W. Changing characteristics of internal environment in the north energy-saving solar greenhouses. Harbin: Northeast Agricultural University, 2015. (in Chinese)

[9] Wu F F, Tana, Bi Y G, Wang Y L, Zhou Y J. Study on the influence of the north wall structure on the temperature field inside greenhouse. Journal of Inner Mongolia Agricultural University: Natural Science Edition 2015; 4: 100-104. (in Chinese)
[10] Wei B, Guo S R, Wang J, Li J, Wang J W, et al. Thermal performance of single span greenhouses with removable back walls. Biosystems Engineering, 2016; 141: 48-57.

[11] Zhang J, Wang J, Guo S R, Wei B, He X L, Sun J, et al. Study on heat transfer characteristics of straw block wall in solar greenhouse. Energy and Buildings, 2017; 139: 91-100.

[12] Wang J W, Li S H, Guo S R, Ma C W, Wang J, Sun J. Analysis of heat transfer properties of hollow block wall filled by different materials in solar greenhouse. Engineering in Agriculture, Environment and Food, 2016; S1881836616300398.

[13] Guan Y, Chen C, Han Y Q, Ling H S, Yan Q Y. Experimental and modeling analysis of a three-layer wall with phase-change thermal storage in a Chinese solar greenhouse. Journal of Building Physics, 2015; 38(6): 548-559.

[14] Yang X L. Thermal environment testing and simulation of Chinese solar greenhouse with brick-polystyrene board compound wall. Yangling: Northwest A\&F University, 2014. (in Chinese)

[15] Song D. Research on soil wall of solar greenhouse and simulation of its temperature environment. Yangling: Northwest A\&F University, 2013. (in Chinese)

[16] Huang X. Studies on variation of soil wall temperature and heat flux in sunken solar greenhouse. Tai'an: Shandong Agricultural University, 2013. (in Chinese)

[17] Huang X, Wang X F, Wei M, Hou J L, Liu FS, Li Q M, et al. Variation patterns of soil wall temperature and heat flux in sunken solar greenhouse. Journal of Applied Ecology, 2013; 24(6): 1669-1676. (in Chinese).

[18] Zhang X G. The quantitative analysis of wall and soil heat storage in solar greenhouse. Taigu: Shanxi Agricultural University, 2015. (in Chinese)

[19] He F, Zhou C J. Analysis on test of wall temperature distribution and heat flux in soar greenhouse. Northern Horticulture, 2015; (10): 58-61. (in Chinese)

[20] Peng D L, Yang Q C, Wei L L, Zhang Y, Fang H. Measurement and heat flux analysis on north earthen wall in Chinese solar greenhouse. Chinese Journal of Agro-meteorology, 2014; 35(2): 168-173. (in Chinese)

[21] Wang Q, Chen J L, Sun Z Q, Zhao Y, Wu M Z, Yang X T, et al. Heat flux analysis of inner surface of north wall in solar greenhouse. Chinese Journal of Agro-meteorology, 2012; 2: 225-229. (in Chinese)

[22] Shi Y L, Wang X F, Wei M, Li Q M, Liu F S, Hou J L. Temperature variation, heat storage and heat release characteristics of soil wall in solar greenhouse. Transactions of the Chinese Society of Agricultural Engineering, 2016; 32(22): 214-221. (in Chinese)

[23] Li J S, Bai Q, Zhang Y H. Analysis on measurement of heat absorption and release of wall and ground in solar greenhouse. Transactions of the Chinese Society of Agricultural Engineering, 2010; 26(04): 231-236. (in Chinese)

[24] Ma C W, Bu Y L, Ji X H, Lu H, Zou L, Wang Y, et al. Method for calculation of heat release at night and evaluation for performance of heat preservation of wall in solar greenhouse. Journal of Shanghai Jiaotong University (Agricultural Science), 2008; 5: 411-415. (in Chinese)

[25] Zhang Z L. Study on the heat transfer characteristics of sunken solar greenhouse soil wall of. Zhengzhou: Henan Agricultural University, 2012. (in Chinese)

[26] Li M, Zhou C J, Wei X M. Thickness determination of heat storage layer of wall in solar greenhouse. Transactions of the CSAE, 2015; 31(2): 177-183. (in Chinese)

[27] Hassan G M, Yahya A, Seyed F R, Mansour M. Solar energy conservation in greenhouse: thermal analysis and experimental validation. Renewable Energy, 2016; 96: 509-519. 